\title{
La ciudadanía europea ante el reto de la unidad política: ¿mero estatuto de libertades o motor para una sólida integración de la Unión Europea?***
}

\section{European citizenship in the face of the challenge of political unit: A mere statute of freedoms or driving force for a solid integration of the European Union?}

RESUMEN

Este trabajo invita a una reflexión sobre el papel actual de la ciudadanía europea en el corazón del debate político y jurídico europeo. Los retos y desafíos que amenazan y minan la unidad de la Unión Europea en la actualidad afectan indefectiblemente a su ciudadanía, desplazándola a un segundo plano y colocándola en una posición de "paro sistémico". En plena celebración del sesenta aniversario del Tratado de Roma y los treinta años de entrada de España en la Unión Europea y la relevante Declaración Schumann, hemos de afrontar un reto todavía pendiente: que los ciudadanos nos identifiquemos cada vez más con la Unión Europea, desarrollando una opinión pública, una conciencia política y una identidad europea.

Profesor doctor en Derecho Público Comparado de la Università degli Studi Roma Tre (Italia) y Research Fellow en la Universidad de Calabria (Italia). Contacto: claudio.dimaio@ unical.it

Profesora e investigadora del Departamento de Ciencia Jurídica y Derecho Público de la Universidad de Castilla-La Macha, doctora en Derecho con mención de doctorado europeo por la Universidad de Castilla-La Mancha (España).Contacto: Ana.Tomas@uclm.es

**** Ponencia presentada en el VII Congreso Internacional en Gobierno, Administración y Políticas Públicas (GIGAPP), en la Mesa de Trabajo G-02, "Retos y desafíos de las Instituciones de la Unión Europea", coordinada por Jorge Juan Morante López y Carmen Ventura Salom. El Congreso fue celebrado en Madrid (España) del 3 al 5 de octubre de 2016.

Recibido el 7 de febrero de 2017, aprobado el 15 de octubre de 2017.

Para citar el artículo: Di MAIO, C. y Tomás, A. La ciudadanía europea ante el reto de la unidad política: ¿mero estatuto de libertades o motor para una sólida integración de la Unión Europea? Derecho del Estado . $^{\circ}$ 40, Universidad Externado de Colombia, enero-junio de 2018, pp. 181208. DOI: https://doi.org/10.18601/01229893.n40.08 
PALABRAS CLAVE

Ciudadanía europea, unidad política, integración, mercado único, inmigración.

ABSTRACT

This article reflects on the current role of European citizenship at the heart of European political and legal debate. Currently, the challenges that threaten and undermine the unity of the European Union inevitably affect his citizenship, moving to a second term and placing it in a position of "systemic arrest". On the 60th anniversary of the Rome Treaty and thirty years of Spain's entry into the EU and the relevant Declaration Schumann, we face a pending challenge, that citizens identify ourselves increasingly with European Union, developing public opinion, political consciousness and a European identity.

KEYWORDS

European citizenship, political unit, integration, single market, immigration.

SUMARIO

Introducción. 1. Las raíces históricas y políticas de la ciudadanía europea. 2. La idea de "ciudadano europeo" en el debate político actual. 3. El homo europeus en la jurisprudencia del Tribunal de Justicia de la Unión Europea. 4. De la crisis financiera al Brexit: los nuevos retos de la ciudadanía de la Unión Europea. Conclusiones. Referencias.

\section{INTRODUCCIÓN}

La Unión Europea se encuentra inmersa en una crisis institucional sin precedentes. Los retos y desafíos que amenazan y minan su unidad política y jurídica (el resurgir de los nacionalismos, las consecuencias del Brexit, la recesión económica, la amenaza terrorista, la crisis de los refugiados, la falta de liderazgo, el giro de Estados Unidos hacia el Pacífico o la amenaza de Rusia, entre otros) afectan indefectiblemente no solo al más que cuestionado concepto de "ciudadanía europea", sino también a la credibilidad del proyecto supranacional de la Unión, y yendo más lejos, a su propia pervivencia. En esta línea, la ciudadanía ligada a la nacionalidad -en su sentido clásico- ha perdido cualquier virtualidad frente a los movimientos migratorios y la crisis de los refugiados que la Unión está viviendo en la actualidad, llegando incluso a convertirla en mero ideal jurídico que invita a ser reformado.

De ahí la importancia de alcanzar un nuevo pacto político, real, visible, duradero y sin fisuras que cree un nuevo concepto de ciudadanía europea 
plenamente inclusivo, que integre a todos por igual y que respete el principio de igualdad basado en la igualdad inherente a toda persona por el simple hecho de serlo. En esta línea, y siguiendo la opinión doctrinal mayoritaria, solo el Tribunal de Justicia de la Unión Europea ostenta la potestad de impulsar o impedir la evolución de la ciudadanía europea como instituto jurídico. Caracterizado por un conjunto de derechos (y al mismo tiempo desprovisto de deberes) que prácticamente pasan desapercibidos para la mayoría de los ciudadanos de los Estados miembros.

De ello deriva el interés por analizar, en el presente trabajo, la función actual del derecho y del entramado institucional comunitario (con carácter general) y del modelo imperante de Estado-nación (de forma específica), en torno al concepto de ciudadanía europea, destacando la desvalorización creciente de ambas nociones en el momento actual; así como su incapacidad para dar respuesta a la protección de los derechos fundamentales de la persona y al mantenimiento del Estado de Bienestar logrado tras la Segunda Guerra Mundial. Una perspectiva liberal y su configuración de la ciudadanía que tal vez hayan quedado obsoletas al mostrarse incapaces de dar respuesta a las sociedades del siglo XXI, caracterizadas por su heterogeneidad y subjetividad en la configuración de los denominados derechos fundamentales de "tercera generación".

Finalmente, mediante el análisis jurisprudencial y de la labor llevada a cabo por el Tribunal de Justicia de la Unión Europea, se tratará de identificar el nivel de desarrollo de esta peculiar y todavía novedosa institución, actualmente atrapada en las instancias procedentes de los ordenamientos nacionales, que aún la perciben como un sencillo atributo del homo economicus, sin tener en cuenta la evidente aparición de otro sujeto moderno, el homo europeus, que corre el riesgo de convertirse en un "personaje en busca de autor".

\section{LAS RAÍCES HISTÓRICAS Y POLÍTICAS DE LA CIUDADANÍA EUROPEA}

De forma simultánea a la creación de la Unión Europea (en adelante UE), como uno de sus elementos constitutivos y a iniciativa española, nace la ciudadanía europea de la mano del Tratado de Maastricht de 1992. Surge como un nuevo instrumento para "reforzar la protección de los derechos e intereses de los nacionales de los Estados miembros" (art. 2 TFUE, actual art. 9 TUE) (Bru, 1994, 169-174). Sin embargo, en rigor, no puede ser considerada una nueva categoría de nacionalidad, sustitutiva de las propias nacionalidades de los Estados miembros, sino más bien un estatuto subsidiario y acumulativo en relación con las mismas (arts. 20.1 TFUE y 9 TUE). Se superpone a la propia del Estado miembro, no afectando en ningún momento a su eficacia jurídico-política. Lo cual significa que los nacionales pueden beneficiarse, asimismo, de un conjunto de derechos suplementarios en el marco jurídico de la UE, que configuran el propio estatuto de la ciudadanía de la Unión (art. 
20.2 TFUE). De este modo, y desde una perspectiva político-jurídica, la UE parte básicamente de la vinculación de la ciudadanía europea a la nacionalidad de sus Estados miembros, creando un "demos múltiple", resultado de la suma del "demos comunitario" y de los "nacionales" de sus socios europeos (Kunoy, 2006, 179).

Dicho principio fue establecido inicialmente en el artículo 8 A del Tratado de Maastricht ${ }^{1}$. Reiterado en el artículo 17 de Tratado de Ámsterdam ${ }^{2}$, en el I-10 del malogrado Tratado Constitucional y consolidado por el vigente artículo 9 del TUE (así como en el art. 20 TFUE) ${ }^{3}$. Jurídicamente se regula a través del Tratado de Funcionamiento de la Unión Europea (arts. 20 a 25) y ha permanecido prácticamente inalterable desde el propio Tratado de Maastricht, sin experimentar grandes avances como institución, excepto la incorporación puntual de nuevos "derechos", como el de iniciativa ciudadana (art. 14, párr. primero TFUE $)^{5}$, o a dirigirse a las instituciones, órganos u organismos de la Unión en la propia lengua y a recibir contestación en dicha lengua (art. 24, párr. cuarto TFUE). Artículos que difícilmente podrían ser calificados como derechos autónomos (Escobar Hernández, 2012, 97).

En este sentido, y en opinión de Arce, el concepto de "ciudadanía" en la UE puede ser analizado tanto desde la vertiente nacional como desde la europea. En el primer supuesto, se maneja la concepción tradicional de ciudadanía. En el segundo, y con una finalidad más pragmática, se pone en marcha la construcción de un novedoso proceso de ciudadanía transnacional, que se ha venido a denominar "ciudadanía europea", incorporando el acervo comunitario a través del tuE. Así pues, es concebido como un paso más en el proceso de integración política iniciado en Europa tras las dos guerras mundiales; aunque más bien, y en rigor, debe ser considerarlo un tímido ensayo de ciudadanía liberal en el marco del Estado-nación, pero mucho

1 Véase Tratado de la Unión Europea (Tratado de Maastricht), firmado el 7 de febrero de 1992 [Diario Oficial de las Comunidades Europeas C191, de 29 de julio de 1992].

2 Véase Tratado de Ámsterdam, firmado en Ámsterdam el 2 de octubre de 1997 [Diario Oficial de las Comunidades Europeas C340, de 10 de noviembre de 1997].

3 Este establece que "será ciudadano de la Unión toda persona que tenga la nacionalidad de un Estado miembro. La ciudadanía de la Unión se añade a la ciudadanía nacional sin sustituirla". Véase ARCE JimÉNEZ, C. Los derechos políticos de los residentes extranjeros: la ciudadanía inclusiva. Sevilla: Defensor del Pueblo Andaluz, 2012, 103.

4 Véase el Tratado de Funcionamiento de la Unión Europea, versión consolidada [Diario Oficial de las Comunidades Europeas C202, de 7 de junio de 2016].

5 El derecho de iniciativa defiende que " $[u] n$ grupo de al menos un millón de ciudadanos de la Unión, que sean nacionales de un número significativo de Estados miembros, podrá tomar la iniciativa de invitar a la Comisión Europea, en el marco de sus atribuciones, a que presente una propuesta adecuada sobre cuestiones que estos ciudadanos estimen que requieren un acto jurídico de la Unión para los fines de la aplicación de los Tratados”, y su regulación secundaria a través del Reglamento (UE) y del Consejo DOCE, Unión Europea. Reglamento (UE) n. ${ }^{\circ}$ 211/2011 del Parlamento Europeo, de 16 de febrero de 2011, sobre la iniciativa ciudadana. [Diario Oficial de la Unión Europea L65, 11 de marzo de 2011, 1-22]. 
más fragmentado, con un alcance más limitado y con una proyección a más largo plazo $(2009,27)$.

En concreto, el estatuto de "ciudadanía de la Unión" reconoce a los particulares: i) el derecho de libre circulación y de residencia en todo el territorio UE (arts. 20.2 a y 21 TFUE); ii) el derecho de sufragio activo y pasivo en las elecciones al Parlamento Europeo y en las elecciones municipales en el Estado en que residan en igualdad de condiciones que los nacionales del mismo (arts. 20.2.b y 22 TFUE); iii) el derecho de petición al Parlamento Europeo, acceso al Defensor del Pueblo Europeo y a dirigirse a las instituciones comunitarias en su propia lengua (arts. 20.2.d, 24, 227 y 228 TFUe y 13 y 55.1 TUE); iv) el derecho de "iniciativa ciudadana" ante la Comisión Europea (arts. 11 TUE y 24 TFUE); y, v) el denominado derecho de protección diplomática y consular en el exterior por parte de cualquier Estado miembro, aunque no sea el suyo, en pie de igualdad con los nacionales de ese Estado (arts. 20.2.c y 23 TFUE). De todos ellos, tan solo este último puede ser considerado un auténtico derecho fundamental. Su equivalencia como derechos humanos fundamentales ha sido reafirmada por la propia Carta de los Derechos Fundamentales de la Unión, incluyéndolos en términos amplios en su mismo articulado.

Por otro lado, el artículo 20.2 TFUE abre la posibilidad de ampliar este catálogo al introducir la expresión "entre otras cosas" antes de detallarlo. Cometido del artículo 25 TFUE, que crea un "procedimiento legislativo especial" en el caso de pretender llevar a cabo dicha ampliación de derechos vinculados a la ciudadanía europea. Para ello es necesaria la unanimidad del Consejo Europeo, la autorización previa del Parlamento y la aprobación en todos los Estados miembros según sus "respectivas disposiciones constitucionales". En cuanto a su alcance jurídico y grado de ejecución efectiva, estos varían mucho de un caso a otro. El motivo ha sido el desigual desarrollo de un proceso normativo de gran alcance para garantizar su eficacia, y que ha tenido lugar en dos frentes: en el ámbito del ordenamiento comunitario y en los nacionales de los Estados miembros. Sin ir más lejos, la primera reforma de la Constitución española estuvo motivada por la introducción del derecho de sufragio pasivo de los ciudadanos de la Unión en las elecciones municipales, que el propio Tribunal Constitucional declaró "no conforme" con el artículo 13.2 de nuestra Carta Magna, en su declaración vinculante 1/1992 del TC, de 1 de julio, como bien recuerda Escobar Hernández $(2012,98)$.

No obstante, en este incipiente proceso de "construcción ciudadana" de la Unión podemos encontrar notables carencias (Arce, 2009, 27). Una muy evidente es la ausencia de una cobertura constitucional para la ciudadanía europea, que actualmente inflige serias heridas a la visión del denominado "patriotismo constitucional" de Habermas $(1998,619-643)^{6}$, pese a los nu-

6 Habermas aportó una nueva dimensión a la noción acuñada por Sternberger, motivado por la tentación de extrapolar mutatis mutandis la experiencia constitucional alemana al con- 
merosos esfuerzos realizados por la UE en las últimas décadas para lograr la tan ansiada legitimidad constitucional. El principal de todos ellos fue el Tratado para la aprobación de una Constitución Europea, rechazado en referéndum en Francia y Holanda en el año 2005. Ambas experiencias, junto a su posterior paralización, han supuesto algunos de los más sonoros fracasos en el proceso de construcción europea en la búsqueda de soluciones para superar las fallas estructurales de la Unión.

Le ha seguido el Tratado de Lisboa ${ }^{7}$, una versión mucho más modesta del inicial Tratado constitucional. Pese a ello, las reticencias ciudadanas volvieron a repetirse en el referéndum de Irlanda, de 13 de junio de 2008, en el que un mayoritario $53,75 \%$ de los votantes rechazó la ratificación del Tratado. De forma paralela, algunas de las normas jurídicas que en fechas recientes están viendo la luz en el seno de la estructura institucional comunitaria continúan cuestionando el supuesto "espíritu fundacional" de la Unión como cuna de valores democráticos y de respeto de los derechos y libertades fundamentales. La mejor muestra de esta preocupante tendencia es la "Directiva sobre procedimientos y normas comunes para el retorno de los nacionales de terceros países que se encuentren ilegalmente en su territorio", más conocida como "Directiva de retorno" o, de forma más crítica, "de la vergüenza"8 (Arce, 2009, 28).

texto de la construcción política europea y, en general, a otros posibles modelos de integración supranacional. En este escenario encuentra incluso un cierto paralelismo entre el caso alemán y la incipiente formulación de la ciudadanía europea, tal como expuso en 1990 en un artículo titulado "Ciudadanía e identidad nacional". La versión definitiva apareció posteriormente en Habermas, J. Facticidad y validez. Madrid: Trotta, 1998, 619-643. Véase, asimismo, Habermas, J. La inclusión del otro. Barcelona: Paidós, 1999, 131-135, y La constelación postnacional. Ensayos políticos. Barcelona: Paidós, 2000; también resultan interesantes las aportaciones al tema que nos ocupa de Lacroix, J. For a European constitutional patriotism. Political Studies, 50 (5), 2002, 944-958; PeCEs-BARBA, G. El patriotismo constitucional. Anuario de Filosofía del Derecho, 20, 2003, 39-62; y STERnBERger, D. Patriotismo constitucional. Bogotá: Universidad Externado de Colombia, 2001.

7 Véase Tratado de Lisboa, firmado en Lisboa, el 13 de diciembre de 2007 [Diario Oficial de la Unión Europea C306, 17 de diciembre de 2007, 1-229].

8 Fue aprobada por el Parlamento Europeo el 18 de junio de 2008 y ratificada por el Consejo a finales del mismo año. Véase anticipadamente la Resolución legislativa del Parlamento Europeo, de 18 de junio de 2008, sobre la propuesta de Directiva del Parlamento Europeo y del Consejo relativa a procedimientos y normas comunes en los Estados miembros para el retorno de los nacionales de terceros países que se encuentren ilegalmente en su territorio [Сом(2005)0391 - C6-0266/2005 - 2005/0167(COD)]. Y, finalmente, véase Directiva 2008/115/CE del Parlamento Europeo y del Consejo, de 16 de diciembre de 2008, relativa a normas y procedimientos comunes en los Estados miembros para el retorno de los nacionales de terceros países en situación irregular. [Diario Oficial de las Comunidades Europeas L348, de 24 de diciembre de 2008, 98-107]. Disponible en: http://www.europarl.europa.eu/meetdocs/2004_2009/documents/dv/ draftreturndirective/DraftReturn Directiveen.pdf También la anterior Directiva 2004/38/CE del Parlamento Europeo y del Consejo, de 29 de abril de 2004, relativa al derecho de los ciudadanos de la Unión y de los miembros de sus familias a circular y residir libremente en el territorio de los Estados miembros. [Diario Oficial de las Comunidades Europeas L158, de 30 de abril de 
Una de sus características más controvertidas la encontramos en el reconocimiento de derechos a los nacionales de los Estados miembros de la UE en el espacio comunitario, donde se arbitran diferentes categorías de derechos, en las que los ordenamientos jurídicos europeos dividen a las personas que residen en los Estados de la Unión. En especial, en torno a los derechos de participación política en elecciones municipales, la libertad de circulación y de residencia, así como a acceder a derechos civiles y sociales en otro Estado diferente al de origen, en pie de igualdad a los propios nacionales del Estado. Ello es fruto de la combinación de los propios procedimientos de ciudadanía europea con los diversos sistemas normativos de ciudadanía de los Estados miembros, que da lugar a un espacio social, político y jurídico desestructurado y desigual en torno al reconocimiento y protección de los derechos fundamentales vinculados a la ciudadanía (Juárez Pérez, 1998, 253-281).

\section{LA IDEA DE “CIUDADANO EUROPEO” EN EL DEBATE POLÍTICO ACTUAL}

En la actualidad, el discurso o debate político en torno a la idea de "ciudadano europeo" no puede resultar baladí y debe ser analizado con rigor, pues forma parte de la misma maquinaria que articula, legitima y, por tanto, construye los límites de nuestra comunidad de Estados europeos, dando forma al que puede ser considerado como el "derecho de todos los derechos" (Muñoz Aunión, 2016, 355). Así lo entiende Pérez Royo al afirmar que la utilización del término "ciudadanía" implica una clara intención política de igualdad entre individuos, que tiende hacia la equiparación jurídica de todos ellos al margen de sus diferencias personales. Y que así se recoge en la propia teoría del Estado constitucional democrático: un modelo de Estado que no puede tolerar que jurídicamente se configuren distintas categorías de individuos jerárquicamente ordenados $(1997,12)^{9}$.

Sin embargo, y tras analizar las raíces históricas y políticas de la UE, se comprueba que la realidad actual en el Viejo Continente es bien distinta. Por lo que, en este sentido, diversos autores opinan que el proyecto comunitario ha superado claramente el reputado concepto de "transición paradigmática" formulado por de Sousa Santos $(2002,244)$, que hace más de una década ponía ya en cuestión el modelo social, político, jurídico y económico impe-

2004, 77], que trataba de ofrecer una respuesta a la fragmentada jurisprudencia del Tribunal de Luxemburgo y de ordenar en un texto único el cuerpo jurídico de la ciudadanía inclusiva en Europa, caracterizado también por su alta dispersión.

9 Véase Pérez Royo, J. En la muerte de Diana de Gales: una reflexión constitucional, en El Pais, jueves 11 de septiembre de 1997, 12, citado en Agudo Zamora, M. La ciudadanía de la Unión Europea. Del artículo 8 del Tratado de la Unión Europea al artículo I-8 del Tratado por el que se instituye una Constitución para Europa. En: CARRILlo, M. y LóPEz BofILl, H. (coords.). La Constitución Europea: Actas del III Congreso Nacional de Constitucionalistas de España. Barcelona: Tirant lo Blanch, 2006, 201-222. 
rante en el mundo occidental desde la Revolución Francesa y, en especial, desde la caída del denominado bloque socialista (Tamayo, 2006, 146-148). En este escenario histórico, la ciudadanía europea fue concebida como un paso más en el proceso de integración política iniciado en Europa tras la Segunda Guerra Mundial. Por primera vez en la historia se "transnacionalizaron" derechos que hasta el momento habían estado siempre conectados a la ciudadanía basada en la nacionalidad y al ámbito político, jurídico y territorial del Estado-nación, usando conceptos cercanos a los posicionamientos de la ciudadanía de residencia.

No obstante, y sin desmerecer este reconocimiento inicial, no es menos cierto que la ciudadanía europea pronto adoleció de serias y graves carencias en el reto de la superación del concepto clásico de la ciudadanía en el marco del Estado-nación. Muchas de ellas motivadas, fundamentalmente, por la falta de interés político de la UE y sus Estados miembros en ampliar el catálogo de derechos de ciudadanía a corto o medio plazo; así como por las propias dificultades para asegurar su virtualidad práctica, dejando fuera de su ámbito a millones de personas que son parte efectiva de la sociedad europea. Sin ir más lejos, a los residentes extranjeros de terceros países ${ }^{10}$.

En esta línea, algunos autores han calificado de "desconcertante" el precepto contenido en el apartado 4 del artículo 52 de la Carta de los Derechos Fundamentales de la Unión Europea, relativo al alcance de los derechos garantizados. En el mismo se recoge el concepto de "derechos fundamentales resultantes de las tradiciones constitucionales comunes a los Estados miembros". Sobre este punto se argumenta que "resulta poco ajustado a la realidad histórica hablar de tradiciones comunes a los Estados miembros, habida cuenta de las historias políticas tan divergentes de los mismos en la era constitucional, que tienen en común su inexistente ejemplaridad democrática" (Linde Paniagua, 2014-2015, 358) ${ }^{11}$. Por lo que es difícil afirmar

10 La expresión "nacional de tercer país" hace referencia a todas las personas que no son ciudadanos de la Unión, es decir, aquellos que no tienen la nacionalidad de un Estado miembro de la Unión Europea. Unión Europea, tal como se recoge en el artículo 17, párrafo 1 del Tratado CE. Véase Tratado Constitutivo de la Comunidad Europea. [Diario Oficial de la Unión Europea C326, 47-390].

11 Como reseña de un pasado que habla por sí mismo: la huella del nazismo en Alemania, del fascismo en Italia, del franquismo en España, del salazarismo en Portugal, o la presencia de coroneles golpistas en Grecia; también el pasado de potencias coloniales como el Reino Unido, Francia o Bélgica; o los crímenes de Estado cometidos en Alemania, España o Italia, que son señalados -en la inmensa mayoría de los Estados de la Unión- como ejemplos de alejamiento de la senda constitucional y de los valores y principios democráticos. O aquellos casos de potencias coloniales como el Reino Unido, Francia y Bélgica, que cometieron numerosos actos de barbarie a lo largo del siglo xx, hasta bien entrados los años sesenta. En concreto, el Reino Unido ha sido condenado reiteradamente por el Tribunal Europeo de Derechos Humanos por la represión en Irlanda del Norte durante muchas décadas en pleno siglo xx. Véase Linde Paniagua, E. Los nuevos retos de la ciudadanía europea. Revista de Derecho de la Unión Europea, 27, julio-diciembre de 2014, y 28, enero-junio de 2015, 358. 
que existan tradiciones comunes de los Estados miembros, como reflejo de las posiciones explícitas y discrepantes del Reino Unido, Polonia, República Checa e Irlanda respecto de algunos contenidos de la Carta. Todo ello sin obviar la relevancia de las constituciones posteriores a la Segunda Guerra Mundial en las que se incluyeron sendos catálogos de derechos fundamentales y, de forma paralela, la pertenencia de los Estados miembros al Consejo de Europa. Institución que, a través del Tribunal de Estrasburgo, ha llevado a cabo una considerable unificación de los derechos fundamentales. Por ende, no podemos reconocer una identidad de regímenes jurídicos previos a la fase de unificación o armonización que, con grandes dificultades, están desarrollando el derecho de la Unión Europea y el Consejo de Europa, pese al etnocentrismo de algunos Estados miembros de la Unión.

Por todo ello, este sistema ha sido duramente criticado por numerosos sectores politológicos, sociales y jurídicos. En especial, el doctrinario, calificándolo de auténtico atentado contra los principios democráticos, la justicia social o el principio mismo de igualdad, al haber facilitado la creación de lo que ha sido denominado "ciudadanos de una sola vía"; es decir, ciudadanos a los cuales se les reconocen todos y cada uno de sus deberes, pero no sus derechos en igual medida. En relación al impacto sobre el principio de igualdad, ha producido una evidente quiebra del mismo en cualquiera de sus dimensiones: liberal (con la prohibición del arbitrio), democrática (prohibición de exclusión de los grupos minoritarios) y, en especial, social (posibilidad de discriminación positiva a favor de los grupos desfavorecidos). Lo cual acaba impactando negativamente sobre la propia dignidad humana y edificando, poco a poco, la denominada "teoría del estigma" (Karst, 1971), que podría desembocar peligrosamente en la justificación de la discriminación y la violación del principio de igualdad como derecho de igual ciudadanía.

$\mathrm{Al}$ amparo de estas lagunas existentes en el derecho comunitario respecto al reconocimiento pleno de los derechos derivados de la ciudadanía europea, se están tomando decisiones políticas que afectan a colectivos de ciudadanos de la UE con especiales problemas de exclusión social (muchos de ellos pertenecientes a minorías étnicas o nacionales que residen fuera de sus países de origen) -sin entrar en detalle en el gravísimo problema de los refugiados-, poco compatibles en nuestra opinión con un proyecto que sirva de instrumento efectivo para el ejercicio de los derechos fundamentales en el ámbito de la UE. De esta forma, y como acertadamente recuerda De Lucas, durante muchas décadas la cuestión migratoria no ha formado parte del epicentro del debate de la ciudadanía europea ${ }^{12}$. Principalmente, por haber

12 No obstante, las implicaciones de la inmigración sobre el desarrollo de la ciudadanía europea no pueden ser minusvaloradas, pues se corre el riesgo de crear una categoría híbrida de ciudadanía cívica. En especial si tenemos en cuenta que los derechos políticos dependen del sentimiento de cohesión de un pueblo europeo, pese a los derechos consagrados a través 
mantenido una visión instrumental y temporal de la inmigración, a modo de Gastarbeiter, que "refuerza la realidad excluyente entre el Nosotros y los Otros" $(2001,65)$. Un claro ejemplo lo encontramos en la reticencia de los Estados miembros en otorgar la ciudadanía a los residentes de larga duración en sus territorios. Mientras esto no ocurra, su integración se verá mermada y la crisis económica podría marginarlos, alejándolos del escenario de la toma de decisiones y arrebatándoles toda posibilidad de participar en el debate político y, por ende, de formar parte de la comunidad política europea (Ruzza, 2000, 145-172).

Este escenario, radicalizado por el blindaje de las fronteras en razón de la guerra contra el terror, el miedo al "diferente" y la percepción de la inmigración como un mal endémico, repercute indefectiblemente en la situación jurídica de los inmigrantes en Europa. Mucho más si tenemos en cuenta el modelo imperante de ciudadanía, que solo permite el pleno disfrute de sus derechos a una minoría selecta de ciudadanos nacionales, que viven y trabajan en otro Estado miembro y que representan en torno a un 1\% de la población total de la Unión. En ese sentido, si la nacionalidad de un Estado miembro dejase de ser la puerta de acceso a la ciudadanía de la Unión, se podría aliviar la responsabilidad que asumen los gobiernos nacionales de facilitar la naturalización y reconocer la doble nacionalidad. Y los nacionales de terceros Estados podrían tener acceso a los beneficios de los derechos de la ciudadanía (Muñón Aunión, 2016, 358-359). En concreto, el de libre circulación, sin tener que adoptar la nacionalidad de un Estado miembro. Asimismo, les permitiría participar en la política europea y contribuir al establecimiento de la Unión Europea de los Pueblos, en la dirección que apunta el Preámbulo del Tratado de Lisboa ${ }^{13}$.

del principio de no discriminación o en la Carta de Derechos Fundamentales. Por ejemplo, en su artículo 20, que establece la igualdad jurídica; así como los artículos del Capítulo V y otros derechos sociales y económicos, cuya extensión debe determinar el TEDH. Por ejemplo, Directiva 2000/43/CE del Consejo, de 29 de junio de 2000, relativa a la aplicación del principio de igualdad de trato de las personas independientemente de su origen racial o étnico [Diario Oficial de las Comunidades Europeas L180, de 19 de julio de 2000, 22-26]; y Directiva 2000/78/CE del Consejo, de 27 de noviembre de 2000, relativa al establecimiento de un marco general para la igualdad de trato en el empleo y la ocupación [Diario Oficial de las Comunidades Europeas L303, de 2 de diciembre de 2000, 16-22]. En el mismo sentido, la Comunicación de la Comisión 757 de 22 de noviembre de 2000, preocupada por la instauración gradual de una ciudadanía cívica. Véase Comunicación de la Comisión al Consejo y al Parlamento Europeo, sobre una política comunitaria de migración [Cом (2000), 757 final].

13 En el Preámbulo del Tratado de Lisboa se afirma: "resueltos a facilitar la libre circulación de personas, garantizando al mismo tiempo la seguridad y la protección de sus pueblos, mediante el establecimiento de un espacio de libertad, seguridad y justicia, de conformidad con las disposiciones del presente Tratado y del Tratado de funcionamiento de la Unión Europea". Sobre las distintas definiciones del concepto de "pueblos" en los Estados miembros, véase STJCE, de 12 septiembre de 2006, Eman y O. B. Sevinger contra College van burgemeester en wethouders van Den Haag [Asunto C-300/04, Rec. 8055, I-44]. 
Por todo ello podemos concluir que todavía nos encontramos lejos de una verdadera ciudadanía equiparable a la de los Estados-nación. Por otro lado, tampoco debemos caer en el error de centrarnos tan solo en el debate sobre la naturaleza convencional o constitucional de la Unión (que tanto gusta a los juristas), ocultando el debate que realmente preocupa a los ciudadanos: la orientación de las políticas comunitarias en las que realmente se compartan valores de solidaridad e igualdad. Cuestión nada baladí; ya que, coincidiendo con la tesis de Weiler, "la Comunidad Europea no ha cruzado aún el umbral de una verdadera Unión social, en la que los pueblos [...] de los Estados miembros sean considerados una comunidad única, con una solidaridad mutua creciente, en donde los ingresos y obligaciones financieras se compartan con independencia de las fronteras nacionales", más allá del debate generado por el crecimiento del turismo por prestaciones sociales, médicas, laborales o educativas hacia la Europa septentrional, que se ha desarrollado a lo largo de la última década y que está generando significativas reformas legislativas en algunos de los Estados miembros de la Unión $(1996,68)$.

En otro orden de cosas, no podemos concluir este epígrafe relativo a la idea de "ciudadano europeo" en el debate político actual sin destacar el relevante papel (cada vez más activo y decisivo) que el Tribunal de Justicia de la Unión Europea está adoptando en la configuración de los nuevos derechos supranacionales, que emanan directamente de la ciudadanía europea para el disfrute de sus ciudadanos y con independencia de la normativa de los países de los que son nacionales. Cuestión que no pasa por alto Gómez de Liaño, al recordar que "en el sistema comunitario de protección de los derechos fundamentales, los acontecimientos se han producido al revés: la garantía jurisdiccional ha precedido a la elaboración de un catálogo escrito de derechos fundamentales y el TJuE ha llevado a cabo durante cuarenta años una protección paradigmática de los derechos al no contar con un instrumento específico de reconocimiento" (2008, 211-231). Un tema relevante, que analizaremos a continuación, aproximándonos a la figura jurídica del homo europeus en la jurisprudencia del tJUE.

\section{EL HOMO EUROPEUS EN LA JURISPRUDENCIA DEL TRIBUNAL DE JUSTICIA DE LA UNIÓN EUROPEA}

La evolución jurisprudencial del concepto de ciudadano europeo constituye un proceso difícil de delinear. Al igual que el resto de las instituciones pertenecientes al proceso de integración supranacional de los Estados miembros, también en este caso existió un período inicial de incertidumbre. Ello se debió a la novedosa (y tal vez ingenua) idea jurídica, que fue discutida en una época en la que las relaciones bilaterales entre algunos de los países europeos era bastante difícil. Más tarde, utilizando el impulso generado por la adopción de una moneda única, emergió una segunda fase donde se produjo un cons- 
tante fortalecimiento orientado hacia la formación de derechos y libertades, accesorios, pero autónomos en su reconocimiento individual. Finalmente, cuando ya la ciudadanía parecía haber logrado una cierta madurez jurídica, la sucesión de diversos y repentinos cambios en el delicado sistema europeo recondujo el proceso hacia un nuevo punto de partida, indefinido, el cual todavía permanece vigente.

Parte de la doctrina afirma que la Europa de Maastricht está en crisis y la situación a la que se enfrentan sus instituciones tiene que ser interpretada como un nuevo capítulo de la historia de este complicado fenómeno jurídico. No obstante, es cierto que las crisis han conducido históricamente a la formación de otras ideas, políticas y formas de diálogo democrático. Solo aceptando el planteamiento de que el período socio-económico actual ha facilitado una interpretación diferente de situaciones jurídicas precedentes podemos entender cuál es el estado de salud de la máxima representación política y de unidad entre los Estados miembros: la ciudadanía europea.

Tal como ya ha sido argumentado en párrafos precedentes, el homo europeus, antes de ser ciudadano de la Unión, ha sido concebido como un sujeto unitario y funcional para la realización de un mercado único en el marco de un espacio de libre circulación, libertad y justicia. Dos matices que es necesario tener siempre presentes a la hora de analizar el alcance de la ciudadanía de la UE. El conjunto de los derechos fundamentales ha sido añadido en la que hemos definido como su "segunda fase" de desarrollo jurídico, habiendo encontrado su principal referente en la Carta de Derechos Fundamentales de la Unión Europea. Lo anterior si es cierto que, en su primer período de vida, los jueces del entonces Tribunal de Justicia de las Comunidades Europeas trataron de definir una conformación inicial de la ciudadanía europea, con el intento de identificar los ámbitos de aplicación y su correlación con la ciudadanía nacional ${ }^{14}$. Por otro lado, es destacado como un extraordinario invento normativo, como "resultado de un proceso que se ha desarrollado con los años a partir de la declaración que el Tribunal de Justicia hizo en su sentencia Van Gend \& Loos, por la que la Comunidad instituye un nuevo ordenamiento jurídico que reconoce generalmente como sujetos no sólo los Estados miembros, sino también sus nacionales" (Mengozzi, 2010, 3).

De este esfuerzo interpretativo se aprecia todo el favor civitatis que el Tribunal europeo ha pretendido perseguir a lo largo de esta primera fase. Esta conducta ha sido dictada no solo por la necesidad de determinar su sindicato ante una institución tan granítica como la ciudadanía nacional, sino por el proceso de "comunitarización" de los asuntos nacionales que se presentaba como prioritario en aquellos años. Respeto al tema que nos ocupa, es decir la evolución del homo europeus, los jueces utilizaron la ciudadanía supranacional

14 Véase la histórica sentencia dictada en el asunto Micheletti (C-369/90), de 7 de julio de 1992 y, por lo tanto, con anterioridad a la entrada en vigor del Tratado de Maastricht. 
para otorgar toda una serie de libertades que, presumiblemente, ya formaban parte de muchos textos constitucionales en Occidente pero no estaban presentes en los de todos los Estados miembros. En cualquier caso, el dato más relevante es que, a través del principio de no discriminación por razón de nacionalidad, el TJUE encontró la fórmula exacta para hacer más eficaces los derechos derivados de las libertades fundamentales consagradas en los Tratados constitutivos de la UE. Del mismo modo, los Estados miembros fueron progresivamente "desposeídos" de un poder histórico: la determinación de una serie de situaciones jurídicas sobre la base de la legislación nacional. En definitiva, la ciudadanía de la Unión empieza a ser calificada como medio para la aplicación efectiva no solo de los artículos contenidos en los Tratados, "sino también de los derechos individuales relacionados con ellos" (De Pasquale, 2012, 460). Así se sembraron las semillas para que el hombre, concebido como "sujeto del mercado", empezara a ser considerado ciudadano de un contexto jurídico supranacional ${ }^{15}$.

Además de los derechos individuales del hombre, se abre el espacio a otra gran conquista del proceso de edificación comunitario, que no es otro que la libertad de establecimiento y estancia en otro país miembro.

Antes de seguir con este tema es necesario aclarar que, a pesar de las buenas relaciones que existían entre muchos de los Estados considerados como "fundadores" de la integración europea, con respecto al delicado ámbito de la migración interna, aún no se percibían muchos de los problemas de calificación jurídica que se presentarían más adelante. Como si la libre circulación se considerara un simple corolario de la realización de un mercado único y no como un estatuto propio del ciudadano europeo. En este sentido, (de nuevo) tuvo que intervenir el TJUE, adelantando una dimensión que políticamente parecía poco definida. Para "incidir" en la parte más íntima de la soberanía estatal (o lo que es lo mismo, el poder de decidir los criterios de acceso a su propio territorio nacional) el Tribunal europeo se decanta por la vía de la no discriminación por razones de nacionalidad, invistiéndose de una fuerza normativa autónoma que ya no es un factor secundario en el diálogo interlegislativo. Es decir que en el ámbito de aplicación de los Tratados (menos restringido que antes) cada ciudadano de la Unión tiene el derecho a circular y residir libremente, sin ningún trato diferenciado respecto al ciudadano nacional, y que pudiese ser contrario al derecho comunitario vigente ${ }^{16}$. Es más, el homo europeus comienza a ser considerado jurídicamente por

15 En este sentido, véase la decisión en el asunto Grzelczyk (C-184/99) de 20 de septiembre de 2001, en la que el Tribunal de Justicia confirma la perspectiva hermenéutica de la valorización del individuo considerado como tal y no como un mero agente económico en relación con el proceso de integración europea.

16 Mediante la sentencia en el asunto Bidar (C-209/03) de 15 de marzo de 2005, la Corte ha reiterado que, siempre con base en el principio de no discriminación por razón de la nacionalidad, la ciudadanía europea no permite una restricción arbitraria del derecho de estancia de 
su naturaleza de migrante, tanto en su condición de trabajador como en su legítima aspiración de conseguir una mejor educación personal y una mayor especialización profesional. Algunas decisiones invaden ciertos poderes que son típicamente reconocidos solo a un Estado soberano en el campo de la educación y la formación profesional, ayudando a configurar la ciudadanía de la Unión como un estado que implica un surplus de garantías y prerrogativas, dentro de los términos establecidos, a favor de nacionales de Estados miembros como tales, y por lo tanto libres de cualquier significación económica ${ }^{17}$.

A partir de este momento, el TJUE empieza a llenar de contenidos implícitos y explícitos una figura normativa que hasta hacía apenas diez años parecía muy pequeña frente a la realización de otros proyectos más ambiciosos. Aquella tentativa de "erosionar" la dura y tal vez inexplorada esfera de la soberanía estatal ya no constituía un tabú para los jueces de Luxemburgo. El Tribunal Europeo dictó importantes decisiones que llegaron a impactar en la tradicional e intangible discrecionalidad estatal respecto de la adquisición y pérdida de la ciudadanía, especialmente en relación con la situación de apátrida. La Corte, poniendo de relieve la inmunidad absoluta del poder del Estado en este ámbito, determina la condición de ciudadano de la Unión, diseñada para representar la posición fundamental de los nacionales europeos, y determina la obligación de los Estados miembros de ejercer su competencia teniendo en cuenta los dictámenes procedentes de la misma ley comunitaria, en virtud de la supuesta autonomía que el estatuto de ciudadano europeo había logrado ${ }^{18}$. A partir de entonces el homo europeus cuenta con un estatuto originario, al margen (y por primera vez) de la consanguinidad o del lugar de nacimiento, reconocido por razones de residencia legítima en el territorio de la UE. Además, esta figura que se añade, pero no sustituye, a la ciudadanía nacional, finalmente es interpretada en su versión más personalista y se aleja de aquella tendencia económica que había caracterizado el desarrollo jurisprudencial de los primeros años. Dando pábulo a la que antes hemos identificado como segunda fase: el período de máxima expansión de la ciudadanía europea,

los ciudadanos "comunitarios", que puede estar sujeto a límites y condiciones, solo en el cumplimiento de la legislación de la Unión y de sus principios generales.

17 Es la actitud que ha inspirado la sentencia en el caso Bressol (C-73/08) de 13 de abril de 2010. Cuando es necesaria una acción de la Unión para alcanzar el objetivo de la no discriminación y si los Tratados no han previsto poderes con este fin, el Parlamento Europeo y el Consejo, de conformidad con el procedimiento legislativo ordinario, podrán establecer disposiciones para facilitar el ejercicio de estos derechos, arbitrando inclusive acciones especiales relativas a la seguridad social o la protección social.

18 Se hace referencia a la histórica sentencia en el asunto Rottmann (C- 135/08), de 2 de marzo de 2010. En ella, los jueces exhortan al legislador nacional para que, a la hora de revocar un título de ciudadanía nacional, consideren que dicho sujeto podría verse perjudicado por perder los derechos procedentes de la ciudadanía de la Unión. En este sentido es importante mantener unos criterios de proporcionalidad, evaluando bien la gravedad de la infracción cometida. 
que llegará a incluir en su ámbito de tutela a los menores y a los familiares procedentes de terceros países, en el marco de la Directiva 2004/38/CE ${ }^{19}$.

La vis expansiva de la ciudadanía europea se manifiesta con toda su fuerza. Empieza a ser determinante en muchos asuntos judiciales y es materia común en algunos otros que exigen un nuevo (y esta vez reaccionario) esfuerzo hermenéutico por parte de los jueces de Luxemburgo. Nos encontramos en el período más relevante y decisivo para entender el desarrollo jurisprudencial de esta institución. Y, aunque no estamos ante un caso de "revolución interpretativa", por primera vez el TJUE se atreve a ampliar los derechos más allá de la simple protección contra la discriminación. Ahora la ciudadanía de la UE orbita alrededor de dos aspectos paralelos y cercanos: el ejercicio de la libre circulación y la salvaguarda de la unidad familiar.

Todo empieza con la celebérrima decisión del asunto Zambrano ${ }^{20}$, que muchos calificaron como una "revolución copernicana" (Cantore, 2011) en el ámbito de la ciudadanía de la UE. A través de esta sentencia, los jueces deciden conceder el derecho de estancia en un Estado miembro a los padres, ambos procedentes de un tercer país, de dos niños nacidos en Bélgica y entonces ciudadanos de la UE. Además del impacto mediático, la sentencia aclara la postura jurídica que la Corte había perseguido desde hacía mucho tiempo. Esta vez no se trata solamente del interés supremo del menor de edad y su consecuente derecho a pertenecer a la unidad del núcleo familiar; ahora el Tribunal estima la pertinencia del derecho de la UE, en referencia al artículo 20 TFUE, cuyo ámbito de aplicación trata de evitar cualquier limitación al disfrute pleno y efectivo de los derechos inherentes a la condición de ciudadano de la Unión, y que ya se había consagrado gracias a la mencionada sentencia Grzelczyk. De esta forma, y resumiendo, la negación del derecho de residencia a unos padres que son ciudadanos de un tercer país y que tienen a su cargo dos menores ciudadanos de un Estado miembro de la UE representa una compresión excesiva de los derechos de estos últimos vinculados a la ciudadanía de la Unión, así como un obstáculo para el disfrute pleno y efectivo de los mismos. Además, al nacional del tercer Estado no se le puede negar un permiso de trabajo, ya que de otro modo no podría obtener los recursos necesarios para cubrir las necesidades básicas del núcleo familiar.

19 La llamada "fase expansiva" fue inaugurada por la decisión en el asunto Zhu y Chen (C-200/02), de 19 de octubre de 2004. Los jueces reconocen a un ciudadano de nacionalidad china, nacido en Irlanda, el derecho de residencia en este país; sin embargo, la Corte también otorga este derecho a la madre como responsable del ciudadano y tutela del menor de edad. El reconocimiento de este derecho deriva del "principio del efecto útil", según el cual las disposiciones del derecho comunitario deben ser interpretadas y aplicadas con el fin de alcanzar plenamente los objetivos que se proponen aplicar.

20 Véase la sentencia en el asunto Gerardo Ruiz Zambrano c. Office National de l'Emploi (C-34/09), de 8 marzo 2011. Para profundizar más sobre su incidencia véase Di MAIO, C. Il criterio del "godimento reale ed effettivo" dei diritti di cittadinanza europea. Considerazioni sull'applicazione della "cláusula Zambrano", 2011. Disponible en: www.duitbase.it 
Como es obvio, la mencionada "cláusula Zambrano" ha generado una ingente cantidad de solicitudes por parte de numerosos extranjeros residentes en el territorio de la UE, padres a su vez de sujetos menores de edad. Esta decisión ha sido posteriormente explicada con mayor amplitud en los asuntos $M c$ Carthy $^{21}$ y Dereci ${ }^{22}$, permitiendo un mayor margen de actuación a la ciudadanía europea, en especial en asuntos que -hasta aquel momento- se habían considerado como exclusivos de los Estados. En cualquier caso, muchos criticaron que el núcleo esencial de los derechos tutelados en el asunto Zambrano fuese tan fecundo de promesas que, hoy en día, "parece una fórmula de 'geometría variable', incapaz de preservar los derechos relativos a la nebulosa existente en torno a la ciudadanía europea" (Rossi, 2011, 1238).

En este sentido, las cuestiones que interesan en torno a la interpretación teleológica de la ciudadanía de la UE son plenamente coincidentes con el fenómeno de la inmigración. La institución supranacional, como era previsible, pasó a convertirse en una "puerta de acceso" para todas aquellas situaciones en las que la tutela de la unidad familiar se conjuga con la necesidad de un permiso de residencia en el Estado de acogida, en concreto, a través de la fórmula de la reagrupación familiar. El homo europeus ya no es solamente el nacional procedente de un Estado miembro de la UE, sino cualquier individuo que elige residir de forma estable en un determinado país (por motivos de estudio, de trabajo o simplemente por decisión personal) y recurre al "escudo" de la ciudadanía de la Unión como válvula de protección para sus derechos individuales y familiares.

A este respecto, la postura del TJUE adopta la cautela necesaria para no subvertir los sistemas nacionales de gestión de la inmigración. Según el TJUE, las solicitudes de residencia para la reagrupación familiar tienen que ser valoradas según lo establecido en la Directiva 2003/86/CE. Por un lado, es cierto que los Estados miembros podrán pedir que el solicitante demuestre tener recursos fijos y regulares suficientes para el mantenimiento propio y de su familia. Por otro lado, esa potestad debe ejercerse a la luz de los artículos 7 y 24, párrafos 2 y 3, de la Carta de los Derechos Fundamentales de la UE, que obliga a los Estados miembros a examinar las solicitudes de reagrupación familiar teniendo en cuenta los intereses de los niños en cada caso concreto, así como la promoción de la vida familiar, con el fin de evitar perjuicios tanto al objetivo de esta directiva como a su efecto útili ${ }^{23}$.

21 StJue, de 5 de mayo de 2011, Shirley McCarthy c. Secretary of State for the Home Department [Asunto C-434/09].

22 STJue, de 15 de noviembre de 2011, Murat Dereci y otros c. Bundesministerium für Inneres [Asunto C-256/11].

23 Es lo que se ha establecido en el asunto Maahanmuuttovirasto (C-356-357/ 11), de 6 de diciembre de 2012, que sigue argumentado las razones que anteriormente habían inspirado las decisiones de los asuntos McCarthy y Dereci, ampliando la responsabilidad del juez nacional 
Si algo se puede apreciar de todo este período de fortalecimiento en torno a la ciudadanía de la $\mathrm{UE}^{24}$ es el intento de los jueces del tJUE (no siempre compartido a nivel nacional) de fortalecer la idea del ordenamiento jurídico original y originario que está presente en los Tratados Constitutivos de la UE y que inevitablemente invade a todas sus instituciones. Del mismo modo, se percibe la intención jurisprudencial (y no tanto política) de avanzar por un camino lento, pero eficaz, hacia la comprensión de la ciudadanía europea como aquella figura política y jurídica autónoma, aunque influyente, en su conjunto de derechos accesorios (desprovisto de deberes) que es sinónimo de participación e inclusión en un Estado miembro para todos los "extranjeros", siempre que dicho país -en el ejercicio de su soberanía- les reconozca un trato idéntico al de sus propios nacionales. Un estatuto europeo investido "solemnemente" por las disposiciones contenidas en los Tratados de la UE, posteriormente reformados por el Tratado de Lisboa (arts. 9 TUE y 20 TFUE) ${ }^{25}$.

\section{DE LA CRISIS FINANCIERA AL BREXIT: LOS NUEVOS RETOS \\ DE LA CIUDADANÍA DE LA UNIÓN EUROPEA}

Como hemos tratado de demostrar, el debate jurisprudencial alrededor de la ciudadanía de la UE ha sido siempre más activo y animado en relación con los documentos declarativos al margen de los principales consejos europeos. No obstante, no hay que caer en el error de creer que todas las posturas adoptadas por el alto Tribunal europeo han sido las más idóneas para ofrecer el adecuado nivel de tutela en el medio y el largo plazo. Junto a esto, solemos pensar que los acontecimientos políticos y financieros no deberían influir en criterios de protección de derechos tan ramificados como son los de ciudadanía. Por ejemplo, conocemos perfectamente cuáles son las medidas que se han tomado en los diferentes niveles de gobierno para frenar los efectos de la crisis financiera y económica que empezó en los años 2007-2008, pero aún no se ha determinado con claridad cuál es la postura adoptada por el TJuE respecto a este mismo período, y en relación con los temas discutidos hasta el momento. Es por ello que estamos a punto de entrar en una "tercera fase", controvertida y caracterizada por el regreso a la idea del Estado-nación y por la difícil interacción entre los distintos grados del poder jurisdiccional.

En concreto, las pautas dictadas por el TJuE a través de sus decisiones más recientes han generado desorientación entre los estudiosos del tema. En más

para averiguar la preexistencia de determinadas características en las solicitudes de reagrupación familiar, a la luz de la Directiva 2003/86.

24 Ante la imposibilidad de mencionar toda la actividad llevada a cabo por el tJuE, véase Morviducci, C. I diritti dei cittadini europei. Torino: Giappichelli, 2011, 49 ss.

25 Nos referimos al fortalecimiento de la ciudadanía europea en todo su articulado, a través del procedimiento de reforma iniciado con la Conferencia Intergubernamental de Niza y culminado el 1 de diciembre de 2009, con la entrada en vigor del Tratado de Lisboa. 
de una ocasión el Tribunal de Luxemburgo ha sido parte activa, anticipando y guiando las decisiones de los Estados miembros que, por su naturaleza, no siempre pueden tener una visión general del ordenamiento supraestatal. Por lo menos es lo que parecía al día siguiente de la sentencia en el conocido asunto $A z i z^{26}$, que anuló los préstamos españoles con cláusulas hipotecarias supuestamente abusivas por parte de muchos actores jurídicos y políticos. Esta postura fue percibida como una declaración del TJUE de presentarse como el guardián de los individuos en tiempos de crisis. Sin embargo, en realidad resulta suficiente examinar otras sentencias menos explícitas pero muy acertadas ${ }^{27}$ para darse cuenta de que la dirección estaba claramente dirigida por la lógica del mercado único, que debía prevalecer sobre los intereses laborales y sociales.

Analizando someramente las decisiones en el marco temporal en el que fueron tomadas, no debería sorprender este regreso extremo a una lectura "auténtica" y literal de los Tratados, que conduce inevitablemente a la defensa de un mercado que, en aquel momento, parecía pasar por su peor época. Pero, lo que más asombra es que, si por un lado los asuntos económicos vuelven a ocupar el epicentro del debate (como no podía ser de otra forma), por otro lado el homo europeus, hasta entonces considerado elemento revestido de una tutela absoluta, retrocede ante la necesidad de proteger no solo a las débiles economías internas, sino también a los mercados del trabajo y a los sistemas nacionales de seguridad social.

Sobre la base de las interpretaciones de algunas sentencias ${ }^{28}$ (que quizás no estuviesen directamente relacionadas con el tema de la ciudadanía por su interés general y su objeto), por su incidencia y su alcance, notamos la inevitable influencia en su desarrollo jurisprudencial. Presuponemos que el TJUE, por su misión y por su naturaleza jurídica, no es comparable con otros tribunales europeos ( ej., el Tribunal Europeo de Derechos Humanos) porque sus actos invaden varios ámbitos jurídicos y deben necesariamente tener en cuenta materias y alcances más amplios (como son la moneda única, la competencia, etc.). Pero es igualmente cierto que, desde 2009, la Carta de Derechos Fundamentales de la UE tiene el mismo poder vinculante que los Tratados constitutivos. Por ello, es lógico preguntarse, al margen de senten-

26 Véase stjue, de 14 de marzo 2013, Mohamed Aziz c. Caixa d'Estalvis de Catalunya, Tarragona i Manresa (Catalunyacaixa) [Asunto C-415/11], donde se establece que la normativa española, que impide al juez competente para declarar abusiva una cláusula de un contrato de préstamo hipotecario suspender el procedimiento de ejecución hipotecaria iniciado por otra vía, es contraria al derecho de la Unión.

27 Véanse, entre muchas, las sentencias en los asuntos Laval (C-341/05) y Rüffert (C-346/06), así como en los asuntos Commission vs. Luxembourg (C-319/06) y Viking Line (C-438/05).

28 Véase lo establecido en el asunto Åkerberg Fransson (C-617/10), de 26 de febrero de 2013. 
cias posteriores ${ }^{29}$, y en una escala de prioridades, en qué posición se coloca la tutela de los derechos individuales para el Tribunal europeo. Lo anterior, siendo conscientes de que la protección de los individuos que siempre ha distinguido al TJUE puede quedar algo mermada (Due, 1994, 123), bajo la fórmula de la "protection du faible" frente a los ataques externos.

En estas ocasiones, el sabio Cicerón afirmaría: "mala tempora currunt, sed peiora parantur", o lo que es lo mismo: "si los tiempos son malos, el horizonte no trae nada bueno para la ciudadanía europea". Ese clima de confusión es fruto de importantes actuaciones llevadas a cabo por determinados países que, como se demostrará más adelante, tendrán un fuerte impacto sobre el desarrollo jurisprudencial del estatuto de origen supranacional. Las últimas decisiones concernientes a la condición jurídica del "extranjero" europeo se han caracterizado por la falta de claridad y por una mayor atención hacia los intereses de los Estados miembros. El Tribunal europeo se ocupa directamente del tema de las prestaciones sociales, en relación con la condición del extranjero residente que, propiamente por estar más afectado por la crisis, se encuentra en una condición subalterna o en búsqueda de trabajo. Con estos pronunciamientos ${ }^{30}$, que constituyen un claro ejemplo del rigor interpretativo sobre la movilidad de los ciudadanos, el TJUE se posiciona en la lucha contra el llamado "turismo social". En concreto, los jueces parecen negar la exigencia de una evaluación global sobre lo que la prestación representaría para el sistema de bienestar social de un Estado miembro, insistiendo sobre el principio de proporcionalidad y de solidaridad financiera entre los nacionales del Estado de acogida y los de los Estados miembros. De hecho, el Tribunal de Justicia (esta vez) deniega la utilización de la Carta de los Derechos Fundamentales y del principio de no discriminación contenido en la misma ${ }^{31}$, excluyendo la aplicación de la legislación de la UE, en virtud del artículo 51 de la Carta, considerando que la concesión de las prestaciones sociales no contributivas está siempre regulada por la legislación nacional.

A este respeto, algunos sugieren que la reciente jurisprudencia del TJUE parece cambiar el enfoque de la Directiva 2004/38/CE ${ }^{32}$, que pretende facilitar el ejercicio del derecho individual a circular y residir libremente, al permitir que las medidas nacionales generales eviten que los ciudadanos de la Unión

29 Por ejemplo, la controvertida decisión en el asunto Digital Rights Ireland (C-293/12 y C-594/12), de 8 de abril de 2014.

30 En concreto, nos referimos a los asuntos Dano (C-333/13), de 11 de noviembre de 2014, y Alimanovic (C-67/14), de 15 de septiembre de 2015.

31 Nótense cómo los mismos argumentos sustentaban la mayoría de las decisiones anteriores.

32 Véase Directiva 2004/38/CE del Parlamento Europeo y del Consejo, de 29 de abril de 2004, relativa al derecho de los ciudadanos de la Unión y de los miembros de sus familias a circular y residir libremente en el territorio de los Estados miembros. [Diario Oficial de las Comunidades Europeas L158, de 30 de abril de 2004, 77]. 
económicamente inactivos (también como grupo) puedan beneficiarse del sistema de protección social del Estado miembro de acogida (Thym, 2015, 17 ss.). Del mismo modo, otros han demostrado que se trata de un cambio sistémico y no de una nueva consecuencia dictada por una diversa interpretación de la legislación (Directiva 2004/38). Más bien es una interpretación autónoma del tuUE (NicShuibhne, 2015, 889 ss.). Siguiendo esta trayectoria, algunos han llegado a la conclusión de que podríamos estar asistiendo a una "fase reaccionaria" (¿otra más?) en la jurisprudencia del tJuE con un retorno hacia el homo economicus (Spaventa, 2016). Desde una perspectiva menos crítica, se ha sugerido adicionalmente un cierto "agotamiento de la ciudadanía" en la práctica del tJue (Sarmiento, 2015, 2 ss.). Lo cierto es que, en esta nueva fase, que consideramos más de precaución que de reacción, el homo europeus tal como lo habíamos imaginado se encuentra atrapado entre las redes de un barco que pesca en el tranquilo mar del proteccionismo, por temor al océano impetuoso (pero fructífero) del método intergubernamental. En todo caso, hay que navegar en aguas ya delimitadas, las del mercado único, donde no está admitida la marcha atrás.

Una parte de la doctrina y de los actores más influyentes justificó esta postura "restrictiva", adoptada tanto a nivel institucional como a nivel jurisdiccional, por la evidente tensión con que la que la UE estuvo a la espera del resultado del referéndum del 23 de junio sobre el denominado Brexit $^{33}$, acerca de la permanencia del Reino Unido en la Unión Europea. En definitiva, como la propia historia nos ha enseñado, por un lado, no todos desean estar sentados siempre en la misma mesa, y por otro, la lancha de salvamento enviada a aquellos que todavía creían en el lema "unidos en la diversidad" finalmente no ha llegado al puerto deseado.

Pero, en términos humanos, ahora el mayor reto relacionado con el Brexit es saber qué ocurrirá con los ciudadanos de la UE en el Reino Unido y, por ende, con los ciudadanos del Reino Unido en la UE. No obstante, no queremos entrar en un debate doctrinal abstracto ${ }^{34}$, pues en nuestra opinión es necesario contar con una determinada seguridad jurídica sobre el tema de debate. Lo cierto es que las dos partes de ese nuevo "Tratado de salida" (UE y Reino Unido) tendrán que negociar la condición jurídica de todos aquellos

33 A través del referéndum se totalizaron más de 16,8 millones de votos a favor de la salida del país de la UE y cerca de 15,7 millones de votos en contra. Téngase en cuenta que, conforme al artículo 50 TUE, se prevé un mecanismo de retirada voluntaria y unilateral de un país de la Unión Europea. El país que decida retirarse, notificará su intención al Consejo Europeo, que negociará la conclusión de un acuerdo para definir las fórmulas de retirada de ese país. Los Tratados dejarán de aplicarse en el país en cuestión solo desde la fecha de entrada en vigor de la retirada o dos años después de la notificación correspondiente.

34 Señalamos que uno de los puntos más debatidos actualmente se refiere al principio internacional de "derechos adquiridos" por ambos sujetos, como se indica en la Convención de Viena sobre el Derecho de los Tratados. 
que, en la actualidad, residen de forma estable y permanente en los distintos territorios. En nuestra opinión, las partes deberán conceder plena efectividad a principios unívocos en la legislación europea o nacional, según sea el caso. Por un lado, es sencillo imaginar que las dos tipologías de sujetos (es decir, los nacionales de origen europeo y los de origen británico) no pueden ser "privadas" de la ciudadanía de la UE por un Estado miembro que decida retirarse. Por otro lado, los Tratados constitutivos califican como ciudadanos de la UE a todos los que son nacionales de los Estados miembros. Entonces, si un país deja de ser un Estado miembro, evidentemente, sus nacionales dejarán de ser ciudadanos de la UE.

Y en todo este caos político-institucional, ¿qué suerte le espera al denominado homo europeus? Respuesta nada sencilla, para lo cual retornamos a nuestra convicción primigenia: las crisis, por lo general, alteran el orden constituido y sugieren a corto plazo medidas para proteger los pilares más sólidos de la arquitectura jurídica e institucional europea. Luego, tras finalizar el período de máxima alerta, favorecen la implementación de los proyectos que quizás anteriormente parecían atrevidos. En este análisis, sintético pero profundo, se ha intentado describir el largo camino de un estatuto o figura normativa (quizás no sustentada por la necesaria participación democrática) que se ha desarrollado paso por paso, con pequeñas conquistas y muchos obstáculos. Por un lado, por la incesante búsqueda de una identidad compartida. Por otro, por la creación de derechos no siempre percibidos como auténticos derechos. Más tarde, por la ampliación de un corpus jurídico que ha tratado de acomodarse a situaciones personales muy diferentes entre sí. Ahora, el reto es superar la fase de paro sistémico ante los acuciantes desafíos de futuro y los ataques procedentes del exterior de la Unión.

En definitiva, la ciudadanía europea ya no es aquel enfant prodige que se vislumbraba en los primeros Tratados constitutivos ${ }^{35}$. Ha de modernizarse atendiendo a las exigencias del pueblo europeo, que no solo está conformado por los nacionales de los Estados miembros, sino también por todas las personas que residen en el territorio de la Unión ${ }^{36}$. Frente al reto de los refugiados, las fuerzas centrípetas de los Estados, las reivindicaciones independentistas y las inevitables incidencias de otros ordenamientos, es indispensable "lograr que el Derecho derivado europeo sitúe y considere al ciudadano como sujeto del

35 Por ejemplo, antes del 1 de mayo 2018, los Estados miembros tendrán que transponer la Directiva 2015/637, de 20 de abril 2015, sobre las medidas de coordinación y cooperación para facilitar la protección consular de los ciudadanos de la UE no representados en terceros países y por la que se deroga la Decisión 95/553/CE [Diario Oficial de la Unión Europea L106, de 24 de abril de 2015, 1-13].

36 En este sentido resulta muy interesante la sentencia en el asunto Dabis (T-529/13), de 10 de mayo de 2016, donde se establece que "el concepto de 'región' debe definirse respetando la situación política, administrativa e institucional existente en los Estados miembros". 
Derecho y no como mero elemento del sistema, para posteriormente poder construir una futurible Comunidad política" (Aguilar Calahorro, 2014).

\section{CONCLUSIONES}

La Unión Europea necesita redefinir los parámetros de transición paradigmática de su ciudadanía. No solo en su doble nivel, epistemológico y social, sino también en tres de sus campos de actuación decisivos: la ciencia, el derecho comunitario y el equilibrio de poderes institucionales y entre sus socios. Porque de nada le sirve a la UE lamentarse por la inexistencia de una conciencia ciudadana europea cuando es más que evidente que los Estados miembros y las instituciones de la Unión no hacen lo suficiente para crearla e incluso, en ocasiones, toman decisiones en la dirección contraria. Por ello, es importante avanzar y dar pasos firmes en el camino para la creación de una conciencia europea y hacia la igualación de derechos entre sus ciudadanos.

Con este fin, y pese a ser conscientes de que las normas son necesarias aunque no sean capaces por sí mismas de cambiar la realidad-, es urgente una renovación jurídica y social que logre dos objetivos: por un lado, incorporar experiencias silenciadas, marginadas, incluso desacreditadas -reconstruyendo la unidad política y el consenso social-, y por otro, buscar alternativas sólidas que tiendan hacia el interés común y no solo en beneficio de los intereses nacionales.

Es relevante recordar que en el momento actual del proceso de construcción de la ciudadanía europea no podemos defender la existencia de una "nacionalidad propiamente europea". Su creación nunca ha figurado en la agenda del proyecto político de la Unión. Por contra, se ha movido más de acuerdo con parámetros próximos a la denominada "ciudadanía de residencia", tratando de avanzar en el reconocimiento de derechos tradicionalmente vinculados a la ciudadanía, en tímida superación al estricto marco del Estado-nación.

Es urgente superar la colonialidad de los poderes comunitarios en toda su extensión, tal y como invita Tamayo, ampliando "los criterios y principios de inclusión social, a través de nuevas sinergias entre igualdad y diferencia que han de reconstruirse multiculturalmente" $(2006,147)$.

Muchas de las medidas que han garantizado la supervivencia de la ciudadanía europea han sido mucho más efectivas cada vez que han sido conjugadas con la protección de los derechos individuales. Abandonar este enfoque dialéctico nos conduciría al riesgo de priorizar los intereses particulares, sacrificando la idea originaria de libertad y justicia contenida en los Tratados constitutivos de la UE y, de forma más profusa, en la Carta de Niza.

Al mismo tiempo, tanto el análisis histórico-político como el desarrollo jurisprudencial nos ponen frente a un proyecto que siempre ha sabido avanzar, aunque fuese "paso a paso", y sirviéndose del valor y de la fuerza de la transformación (a menudo erosiva), que ha sido capaz de modernizar y 
hacer más democrática y participativa la ya delicada integración europea. No podemos olvidar que la UE no nace como confederación de Estados, ni como una organización internacional perfectamente estructurada. Nos encontramos más bien ante un complejo "experimento jurídico" que requiere ser retroalimentado constantemente a lo largo de los años.

Es necesario imaginar un nuevo modelo de gobernanza de la UE, que sepa salvaguardar las diferencias nacionales en un mundo globalizado que demanda cada vez mayor fuerza y unidad política e institucional. En ocasiones las crisis se convierten en oportunidades y no deben ser utilizadas para defender posiciones antiguas y obsoletas. $\mathrm{Si}$, por un lado, los Estados miembros son quienes deciden sobre el futuro de los Tratados, por otro lado es necesario impulsar la búsqueda de un mecanismo más apropiado de modificación de los Actos constitutivos que, especialmente en el momento actual (tras los retos dimanantes del Brexit), no pueden ignorar los cambios que demanda la ciudadanía europea.

Hay que retornar al camino del homo europeus. Pero para lograr ese importante y necesario objetivo todos debemos hacer esfuerzos. Las instituciones comunitarias, por su parte, tendrían que solventar sus "puntos ciegos" y buscar un mayor diálogo con todos los niveles de la dirección intergubernamental en el marco de las instituciones europeas. Los ciudadanos, por nuestra parte, deberíamos ser más conscientes de que ya formamos parte del "Pueblo europeo" y de un "Proyecto europeo común", y de que en este proceso ya no hay vuelta atrás. Por esta razón, debemos utilizar todas las herramientas de interacción que nos proporciona la legislación europea (no solo la libre circulación), porque un pueblo puede que no tenga las mismas tradiciones y no hable el mismo idioma, pero permanece unido a la hora de encontrar un refugio bajo el mismo "techo": el techo europeo.

En conclusión, la construcción de una comunidad política requiere de un intenso proceso constitucional, en el que se afirmen los valores de una eficaz y eficiente Rule of Law, sin olvidar que un Estado de derecho no puede ser "de cualquier Derecho, sino de un Derecho que sea a la vez democrático y social” (Balaguer Callejón, 2011).

\section{REFERENCIAS}

Agudo Zamora, M. (2006). La ciudadanía de la Unión Europea. Del artículo 8 del Tratado de la Unión Europea al artículo I- 8 del Tratado por el que se instituye una Constitución para Europa. En: CARrillo, M. y López Bofill, H. (coords.). La Constitución Europea: Actas del III Congreso Nacional de Constitucionalistas de España. Barcelona: Tirant lo Blanch, 201-222.

Aguilar Calahorro, A. (2014). Los ciudadanos en la UE: ¿sujetos u objetos del derecho europeo? Sobre identidad, democracia y participación en la UE. KorEuropa, 5, 16-34. 
Arce Jiménez, C. (2012). Los derechos políticos de los residentes extranjeros: la ciudadanía inclusiva. Sevilla: Defensor del Pueblo Andaluz, 103-111.

ArCe Jiménez, C. (2009). La ciudadanía en la era de la globalización: el reto de la inclusión. Madrid: Editorial Universitaria Ramón Areces.

Balaguer Callejón, F. (2011). Derecho y justicia en el ordenamiento constitucional europeo. Revista de Derecho Constitucional Europeo, 16, 261-282.

BRU, C. M. (1994). La ciudadanía europea. Madrid: Sistema.

Cantore, C. M. (2011). La sentenza Zambrano della CGUE: una 'rivoluzione copernicana'? Disponible en: www.diritticomparati.it

De Lucas Martín, J. (2001). Hacia una ciudadanía europea inclusiva. Su extensión a los inmigrantes. Revista СIDов d'Afers Internacionals, 53, 63-75.

De Pasquale, T. (2012). Problemi interpretativi della nozione giuridica di cittadinanza: un concetto "europeizzato" di diritto pubblico interno? La controversa relazione tra cittadinanza dell'Unione Europea e cittadinanze nazionali degli Stati membri. Rivista Italiana di Diritto Pubblico Comunitario, 3-4, 445-480.

De Sousa Santos, B. (2003). Crítica de la razón indolente. Contra el desperdicio de la experiencia. 1. Bilbao: Desclée de Brouwer.

De Sousa Santos, B. (2005). El milenio huérfano. Ensayos para una nueva cultura política. Madrid: Trotta.

De Sousa Santos, B. (2002). Para uma sociología das ausências e uma sociología das emergencias. Revista Crítica de Ciências Sociais, 63, octubre, 237-280.

Di MAio, C. (2011). Il criterio del "godimento reale ed effettivo" dei diritti di cittadinanza europea. Considerazioni sull'applicazione della "clausola Zambrano". Disponible en: www.duitbase.it

Due, O. (1994). The Law-making Role of the European Court of Justice Considered in Particular from the Perspective of Individuals and Undertakings. Nordic Journal of International Law, 63, 1, 123-137.

Escobar Hernández, C. (2012). La ciudadanía y los derechos fundamentales en la Unión Europea. En: Escobar Hernández, C. (dir.). Instituciones de la Unión Europea. Valencia: Tirant lo Blanch, 89-106.

Gómez de Liaño, M. (2008). La protección jurisdiccional de los derechos fundamentales en la Unión Europea. Revista de Derecho de la Unión Europea, 15, 2008, 211-231.

Habermas, J. (2000). La constelación postnacional. Ensayos políticos. Barcelona: Paidós.

Habermas, J. (1999). La inclusión del otro. Barcelona: Paidós, 131-135.

Habermas, J. (1998). Facticidad y validez. Madrid: Trotta, 619-643.

Jú́rez Pérez, P. Nacionalidad estatal y ciudadanía europea. Barcelona: Marcial Pons. 
Karst, K. (1971). Equal Citizenship under the Fourteenth Amendment. Harvard Law Review, 191, noviembre, 1-68.

Kunoy, B. (2006). An Union of National Citizens: The origin of Courts lack of avantgardism in the Chen case. Common Market Law Review, 43, 179-190.

Lacroix, J. (2002). For a European constitutional patriotism. Political Studies, 50 (5), 944-958.

Linde Paniagua, E. (2015). Los nuevos retos de la ciudadanía europea. Revista de Derecho de la Unión Europea, 27, julio-diciembre 2014 y 28, enero-junio 2015, 341-360.

Mengozzi, P. (2010). La cittadinanza dell'Unione e il contributo della Corte di Giustizia alla precisazione dell'identità europea. En: BARUFF, M. C. (ed.). Cittadinanza e diversità culturale nello spazio giuridico europeo. Padova: Cedam.

Morviducci, C. (2011). I diritti dei cittadini europei. Torino: Giappichelli.

Muñoz Aunión, A. (2016). Sobre la ciudadanía en el derecho internacional. Revista Bolivariana de Derecho. 21, 352-373.

Nic Shuibhne, N. (2015). Limits rising, duties ascending: The changing legal shape of Union citizenshi Common Market Law Review, 52, 889-938.

Peces-Barba, G. (2003). El patriotismo constitucional. Anuario de Filosofía del Derecho. 20, 39-62.

Pérez Royo, J. (1997). En la muerte de Diana de Gales: una reflexión constitucional. El País, 11 de septiembre, 12.

Rossi, S. (2011). Il caso McCarthy: la cittadinanza europea e la cruna dell'ago. Diritto Pubblico Comparato ed Europeo, III, 1238-1244.

Ruzza, C. (2000). Anti-Racism and EU Institutions. Journal of European Integration, 2, 2000, 145-172.

$\breve{S}_{A d L}$, U. y Rask Madsen, M. (2016). Did the Financial Crisis Change European Citizenship Law? An Analysis of Citizenship Rights Adjudication before and after the Financial Crisis. European Law Journal, 22, 1, 40-60.

Sarmiento, D. (2015). Citizenship fatigue at the Court of Justice? Disponible en: despiteourdifferencesblog.wordpress.com

Spaventa, E. (2016). Earned citizenship: Understanding Union Citizenship through its Scope. En: Kochenov, D. (ed.). Citizenship and Federalism in the European Union: The Role of Rights. Cambridge, Cambridge University Press.

Sternberger, D. (2001). Patriotismo constitucional. Bogotá: Universidad Externado de Colombia.

Tamayo, J. J. y de Sousa Santos, B. (2006). El milenio huérfano. Ensayos para una nueva cultura política. Revista Crítica de Ciências Sociais. 74, 145-150. 
Thyм, D. (2015). The elusive limits of solidarity: Residence rights of and social benefits for economically inactive Union citizens. Common Market Law Review. 52, 17-50.

Tomaselli, A. (2014). Cittadinanza, libertà di circolazione, diritti umani nella giurisprudenza della Corte di giustizia dell'Unione europea: riflessioni e prospettive. KorEuropa. 4, 164-199.

WeILER, J. H. H. (1996). European citizenship and human rights. En: Winter, J. A.; Curtin, D. M.; Kellermann, A. E. y y De Witte, B. (eds.). Reforming the treaty on European Union. The legal debate. The Hague, Kluwer Law International, 57-68.

\section{Fuentes normativas}

Unión Europea

\section{Comisión Europea}

Comunicación de la Comisión al Consejo y al Parlamento Europeo, sobre una política comunitaria de migración. [Сом (2000), 757 final, de 22 de noviembre de 2000].

\section{Consejo Europeo / Parlamento Europeo}

Directiva (UE) 2015/637 del Consejo, de 20 de abril 2015, sobre las medidas de coordinación y cooperación para facilitar la protección consular de los ciudadanos de la UE no representados en terceros países y por la que se deroga la Decisión 95/553/CE. [Diario Oficial de la Unión Europea L106, de 24 de abril de 2015, 1-13].

Reglamento (UE) n..$^{\circ}$ 211/2011 del Parlamento Europeo, de 16 de febrero de 2011, sobre la iniciativa ciudadana. [Diario Oficial de la Unión Europea L65, de 11 de marzo de 2011, 1-22].

Directiva 2008/115/CE del Parlamento Europeo y del Consejo, de 16 de diciembre de 2008 , relativa a normas y procedimientos comunes en los Estados miembros para el retorno de los nacionales de terceros países en situación irregular. [Diario Oficial de las Comunidades Europeas L348, de 24 de diciembre de 2008, 98-107].

Resolución legislativa del Parlamento Europeo, de 18 junio de 2008, sobre la propuesta de Directiva del Parlamento Europeo y del Consejo relativa a procedimientos y normas comunes en los Estados miembros para el retorno de los nacionales de terceros países que se encuentren ilegalmente en su territorio [сом(2005)0391 - C6-0266/2005 2005/0167(COD)].

Directiva 2004/38/CE del Parlamento Europeo y del Consejo, de 29 de abril de 2004, relativa al derecho de los ciudadanos de la Unión y de los miembros de sus familias a circular y residir libremente en el territorio de los Estados miembros. [Diario Oficial de las Comunidades Europeas L158, de 30 de abril de 2004, 77].

Directiva 2003/86/CE del Consejo, de 22 de septiembre de 2003, sobre el derecho a la reagrupación familiar. [Diario Oficial de las Comunidades Europeas L251, de 3 de octubre de 2003, 12-18]. 
Directiva 2000/78/CE del Consejo, de 27 de noviembre de 2000, relativa al establecimiento de un marco general para la igualdad de trato en el empleo y la ocupación. [Diario Oficial de las Comunidades Europeas L303, de 2 de diciembre de 2000, 16-22].

Directiva 2000/43/CE del Consejo, de 29 de junio de 2000, relativa a la aplicación del principio de igualdad de trato de las personas independientemente de su origen racial o étnico. [Diario Oficial de las Comunidades Europeas L180, de 19 de julio de 2000, 22-26].

\section{Fuentes jurisprudenciales}

\section{Tribunal General de la Unión Europea}

Sentencia del Tribunal General, de 10 de mayo de 2016, Balázs-Árpád Izsák y Attila Dabis c. Comisión [Asunto T-529/13].

Tribunal de Justicia de la Unión Europea

STJUE, de 15 de septiembre de 2015, Jobcenter Berlin Neukölln c. Nazifa Alimanovic y otros [Asunto C-67/14].

StJue, de 11 de noviembre de 2014, Elisabeta Dano, Florin Dano c. Jobcenter Leipzig [Asunto C-333/13].

STJue, de 8 de abril de 2014, Digital Rights Ireland [Asuntos acumulados C-293/12 y C-594/12].

STJue, de 14 de marzo 2013, Mohamed Aziz c. Caixa d'Estalvis de Catalunya, Tarragona i Manresa (Catalunyacaixa) [Asunto C-415/11].

STJUE, de 26 de febrero de 2013, Åklagaren c. Hans Akerberg Fransson [Asunto C-617/10].

STJUE, de 6 de diciembre de 2012, O. y S.c. Maahanmuuttovirasto y Maahanmuuttovirasto c. L. [Asuntos acumulados C-356-357/ 11].

STJUE, de 15 de noviembre de 2011, Murat Dereci y otros c. Bundesministerium für Inneres [Asunto C-256/11].

STJue, de 5 de mayo de 2011, Shirley McCarthy c. Secretary of State for the Home Department [Asunto C-434/09].

STJue, de 2 de marzo de 2010, Janko Rottman c. Freistaat Bayern [Asunto C- 135/08].

STJue, de 13 de abril de 2010, Nicolas Bressol y otros y Céline Chaverot y otros c. Gouvernement de la Communauté française [Asunto C-73/08].

STJCE, de 19 de junio de 2008, Comisión de las Comunidades Europeas c. Gran Ducado de Luxemburgo [Asunto C-319/06].

STJCE, de 11 de diciembre de 2007, International Transport Workers' Federation yt Finnish Seamen's Union c. Viking Line ABP y OÜ Viking Line Eesti [Asunto C-438/05]. 
STJCE, de 3 de abril de 2007, Dirk Rüffert c. Land Niedersachsen [Asunto C-346/06].

STJCE, de 12 septiembre de 2006, Eman y O. B. Sevinger c. College van burgemeester en wethouders van Den Haag [Asunto C-300/04, Rec. 8055, I-44 ].

STJCE, de 18 de diciembre de 2005, Laval un Partneri Ltd c. Svenska Byggnadsarbetareförbundet y otros [Asunto C-341/05].

STJCE, de 15 de marzo de 2005, The Queen, a solicitud de Dany Bidar c. London Borough of Ealing y Secretary of State for Education and Skills [Asunto C-209/03].

STJCE, de 19 de octubre de 2004, Kunqian Catherine Zhu y Man Lavette Chen c. Secretary of State for the Home Department [Asunto C-200/02].

STJCE, de 20 de septiembre de 2001, Rudy Grzelczyk c. Centre public d'aide sociale d'Ottignies-Louvain-la-Neuve [Asunto C-184/99].

STJCE, de 7 de julio de 1992, Mario Vicente Micheletti y otros c. Delegación del Gobierno en Cantabria [Asunto C-369/90]. 